\title{
ANALYSIS OF THE IMPACT OF OCCUPATIONAL HEALTH AND SAFETY RISKS ON THE SUSTAINABILITY OF ROMANIAN ORGANIZATIONS UNDER THE SARS-COV-2 PANDEMIC
}

\author{
Mihaela Cornelia Sandu ${ }^{1}$ \\ Valentin Mihai Leoveanu ${ }^{2}$
}

DOI: https://doi.org/10.31410/LIMEN.2020.75

\begin{abstract}
In the current difficult economic and social situation in Romania and worldwide characterized by the health crisis caused by the evolutions of the SARS CoV-2 pandemic, the present study aims to highlight the amplitude to which the risk of occupational health and safety influences the continuity and sustainability of business in Romania. The research methodology adopted by the authors was based on the research highlighted in the specialized literature and by considering firstly the analysis of the results of the survey realized by applying a questionnaire to the employees from different fields of activity during the period February 29 March 15, 2020. Secondly, the authors considered the analysis of the determinants of the risk of occupational health and safety at the level of the employers with an impact on the continuity and sustainability of the Romanian organizations, especially the businesses. The results of this research reveal how the working hypotheses in the second level of the analysis were confirmed or not regarding the impact of occupational and healthy risks on the sustainability of Romanian organizations under the SARS-COV-2 pandemic.
\end{abstract}

Keywords: Occupational health and safety risks, Business sustainability, SARS CoV-2 pandemic, Working remotely.

\section{INTRODUCTION}

$\lceil$ n $\mathrm{n}$ the current difficult economic and social situation in Romania and worldwide characterized by the health crisis caused by the evolutions of the SARS CoV-2 pandemic, the present study aims to highlight the amplitude to which the risk of occupational health and safety influences the continuity and sustainability of business in Romania. The authors start in their research on the premise that male employees and young employees are less concerned about their jobs. It also started from the assumption that good communication from the employer, as well as the possibility for employees to work remotely, both cause employees to be less concerned about the fact that their workplace will be affected by the SARS CoV-2 pandemic.

The research methodology adopted by the authors was based on the research highlighted in the specialized literature and by considering firstly the analysis of the results of the survey realized by applying a questionnaire to the employees from different fields of activity during the period February 29 - March 15, 2020. The questionnaire used in this paper is structured in two parts: first part about the impact of SARS-COV-2 on Romanian employees and the second part about demographical elements. We distributed the questionnaire on social media networks (Facebook and LinkedIn). Secondly, the authors considered the analysis of the determinants of the risk of

University of Bucharest, 4-12, Blvd. Regina Elisabeta, etaj 1, sector 3, Bucharest, Romania

University of Bucharest, 4-12, Blvd. Regina Elisabeta, etaj 1, sector 3, Bucharest, Romania 
occupational health and safety at the level of the employers with an impact on the continuity and sustainability of the Romanian organizations, especially the businesses. Data that we collected based on this questionnaire were entered into R Studio and Excel. The authors developed a descriptive statistic for the questions of the questionnaire and then, they tested the hypothesis above.

\section{LITERATURE REVIEW}

A general analysis of the occurrence and effects of the health crisis triggered by the November 2002 SARS CoV-1 pandemic in China was conducted by Lam et al. (2003) highlighting as the main lessons for public authorities, for the population, as well as for business people worldwide: "(1) any outbreak of infectious disease can rapidly spread around the world by air travel; (2) early reporting of the outbreak to neighboring countries/regions and the World Health Organization is essential to prevent international spread; and (3) infection control, tracing and quarantine of contacts are essential to control the epidemic" (Lam et al., 2003).

An article published by Jiang (2009) highlights the socio-psychological effects on human communities, in particular the Chinese community in Europe, produced by the health crisis caused by the spread of the SARS CoV-1 virus in 2002-2003. The study offers a view regarding the way in which, individually and at group level, the situation was managed, but also regarding the behavioral model thus offered by these communities that can serve as a template in the elaboration of the response strategies of the governments and the health leaders.

The authors Itzwerth, Moa \& MacIntyre (2018) researched the 2009 influenza pandemic response plans in Australia, designed by public authorities at the national, state, or territorial level, by monitoring based on thirteen specified criteria. The study ultimately highlighted that "pandemic response would be more effective if plans were standardized, clear, and were to include overlooked dimensions of a pandemic's impact as well as guidance for specified endusers" (Itzwerth, Moa \& MacIntyre, 2018)

Preliminary research by the authors Rebman, Wang, Swick and Reddic together with del Rosario (2013) regarding the responsiveness of businesses to the emergence and pandemic developments associated with the spread of viruses and to ensuring business continuity has highlighted as determinants: dimension business, the type of business, the association of human resources specialists in the planning and implementation of response plans and the perception of pandemic risk in the coming years.

Subsequently, a larger study by Rebmann et al. (2013) was based on applying a questionnaire addressed to human resources specialists and on carrying out an econometric analysis based on logistical and linear regressions in order to highlight the importance of the influencing factors regarding the implementation of decisions, personnel management, vaccination policy. The conclusions revealed, on the one hand, the great importance given to these factors at the level of the big businesses as compared to the smaller interest granted to them by the smaller businesses, an explanatory fact, and, on the other hand, they reflected the increasing attention that must be shown to pandemic plans to prepare for the next biological event (i.e., pandemic, bioterrorism attack, or emerging infectious disease outbreak)" (Rebmann et al., 2013).

The issue of the negative effects caused by the illness of the employees as a result of the H1N1 pandemic, highlighted by the study of the impact of the absence of the employees from the workplace, is reflected in the article of the authors Tora-Rocamora et al. (2012). The paper 
presents as the main consequences the emergence of malfunctions regarding the daily operations, as well as the increase of the operational costs, with negative implications on the continuity of the activity and the sustainability of the company.

Blake, Blendon and Viswanath (2010) underline the important role that companies (businesses) play in protecting the health and safety of employees, conducting a study on how employees adapt and respond to the conditions imposed by employers as a result of influenza pandemic manifestation. The research was based on the application of the Harvard School of Public Health questionnaire on the 2006 pandemic influenza and the use in econometric calculations of multivariable logistic regression, leading to the conclusion that "inability to work from home, lack of paid leave and income" are determining factors in ensuring the stability of the workforce and the continuity of the business during the manifestation of a national health crisis.

At the Harvard Global Health Institute, a more recent study warns of the negative economic consequences of "closing companies, schools, public institutions, and often even health institutions" as well. "Interruptions in the transport of goods, commercial activities and tourism". The study proposes an action framework on four areas of interest, such as: "1. Strengthening the primary capacity of the public health system; 2. Improve science, technology and access to them; 3. Strengthening the analysis of risks and incentives for action; and 4. Strengthening global mechanisms (institutions such as the UN and WHO)" (Harvard Global Health Institute, 2018).

Smith, Hansen, and Spanbauer surveyed several businesses in the city of Omaha, Nebraska, regarding the preparation of companies for pandemic influenza and disaster preparedness, which revealed that "most businesses have Pandemic flu planning started, but few practiced the plan or used it to train employees." (Smith, Hansen, and Spanbauer, 2007).

Another revealing research for the present study is that of Watkins, Cooke and Donovan, who points out the importance of preparing for emergencies such as pandemics and establishing concrete response plans at the community level. Using semi-structured face-to-face interviews and applying binomial logistic regression analysis, the paper reveals that "small and mediumsized enterprises in Australia are not currently well prepared for the pandemic influenza. We have found that beliefs about risk, severity and the ability to respond effectively to the threat of pandemic influenza are important predictors of preparedness." (Watkins, Cooke and Donovan, 2007).

Based on previous research above, Watkins et al. (2008) conducted a new analysis of how managers and entrepreneurs from small and medium-sized enterprises manage to identify pandemic risks, plan and apply response measures to manifest such risks. In this context, the findings of the study revealed that "there is a perceived inability of participants to effectively prevent or control the spread of influenza in their workplace" (Watkins et al., 2008), essential in terms of awareness and management training for planning response.

Dunkan in his article (Duncan, 2007) reflects in parallel the situation of a plan to respond to possible influenza pandemics at the level of US and Canadian companies and underlines the opportunity to prepare early for this situation in order to reduce the economic and social risks at the level of society, as well as ensuring business continuity. The research results focus on "developing a framework for pandemic preparedness at the organization level, including ensuring the health and well-being of employees, ethical and legal issues, business continuity and partnering with government and civil society." (Duncan, 2007). 
In a study by authors Murphy, Friesner and Rosenman (2014), they highlight how companies had to cope with both the difficult economic situation and the pandemic influenza crisis, which led to different responses in intensity and effects. The study concludes that the managers have responded proactively in the event of economic difficulties with the manifestations of the influenza pandemic precisely because of a better knowledge of the response modalities and their implementation, of the more effective control in the first situation. As a result, the preparation and planning of action measures at the business level regarding the manifestation of future potential pandemics is a pressing necessity for managers.

The work of Beaton et al. (2007) analyses risk planning at the university level and highlights "gaps in pandemic influenza plans and policies at the university level, including issues related to isolation and quarantine, continuity of operations, disaster psychology services, integration volunteers in disaster response actions, monitoring student trips and university staff, communication problems and ways to meet the needs of the resident and foreign students and teachers during an outbreak." (Beaton et al., 2007).

A very special reference related to the present research is the work of Lee et al. (2010) who try to present the positive effects of the vaccination process of employees in the context of the flu pandemic. The results of the study show that disregarding employee vaccination measures can lead to substantial decreases in labor productivity and that applying timely vaccination to at least $20 \%$ of the workforce of large companies can have positive effects on job losses productivity.

A recent article by Ahmed et al. (2020), which analyzed the determinants of the presence of employees at work at the beginning of the 2017-2018 influenza season, emphasized that "compared with workers without a telework option, those with telework access worked more days during illness overall, but there was no difference in days worked at the usual workplace". The study revealed the need to use "paid leave benefits, as well as business practices that actively encourage employees to stay at home" (Ahmed et al., 2020), in order to prevent the spread of the pandemic and ensure the health and safety of employees at work.

The authors' Smith, Keogh-Brown, Barnett and Tait pointed out in their study (Smith et al., 2009) as a corollary of their research that: "balancing school closure against ,business as usual' and obtaining sufficient stocks of effective vaccine are more important factors in determining the economic impact of an influenza pandemic than is the disease itself. Prophylactic absence from work in response to the fear of infection can add considerably to the economic impact." (Smith et al., 2009).

As an important reference element in the present study, it is highlighted that there is a legislative regulation at the European level Directive 89/391 - the Framework Directive on safety and health at work, which considers "the implementation of measures to promote the improvement of safety and health". workers at work" (Directive 89/391 EU, 1989). This Directive is also associated with others on the same subject, namely: Directive 89/654 / EEC (jobs), Directive 89/655 / EEC (work equipment), Directive 89/656 / EEC (individual protective equipment), Directive 90/269 / EEC (manual handling of loads) and Directive 90/270 / EEC (working on the monitor), which have influenced and influence the national legislation of the Member States in the field. Romania, as a Member State of the European Union as of January 1, 2007, is subject and must comply primarily with the European legislation in force so that the provisions contained in this legal regulation are also essential for Romanian employers. The provisions of Directive 89/391 take into account, inter alia: "the establishment of a uniform level of safety 
and health for the benefit of all workers", "obliges employers to take appropriate preventive measures to increase the safety and health of the workplace" and "introduces the principle as a key element risk assessment and defines its main elements (for example, hazard identification, worker participation, the introduction of appropriate measures with priority to eliminate risk at source, periodic documentation and reassessment of workplace hazards)" (Directive 89/391 EU, 1989).

Regarding the national legislation on occupational safety and health at work, Romania has three major levels of legislation: primary, secondary and tertiary legislation. The main regulation at the national level in this field (primary legislation - general principles) is Law no. 319 of July 14, 2006, on Occupational Safety and Health amended on September 27, 2010. It is added as secondary legislation (preventive measures, enforcement rules), a series of Government Decisions and Standards, and on the third level (Tertiary legislation) employers' own OSH instructions.

\section{RESEARCH METHODOLOGY}

The research methodology adopted by the authors was based on the research highlighted in the specialized literature and by considering firstly the analysis of the results of the survey realized by applying a questionnaire to the employees from different fields of activity during the period February 29 - March 15, 2020. Secondly, the authors considered the analysis of the determinants of the risk of occupational health and safety at the level of the employers with an impact on the continuity and sustainability of the Romanian organizations, especially the businesses.

Regarding the second level of the analysis, the following working hypotheses were outlined:

Hypothesis One: There is a direct relation between employees' concern that their workplace will be affected by the SARS CoV-2 pandemic and how well government respond to them concern.

Hypothesis Two: Employees are less concerned that their workplace will be affected by the SARS CoV-2 pandemic if the employer established a specific communication strategy regarding this medical crisis than the reverse case.

Hypothesis Three: Employees are less concerned that their workplace is affected by the SARS CoV-2 pandemic if employer provides them the opportunity to work remotely.

Hypothesis Four: Employees from Bucharest are more concerned than those from the rest of the country that their workplace will be affected by the SARS CoV-2 pandemic.

Hypothesis Five: Women employees are more concerned than men employees that their workplace will be affected by the SARS CoV-2 pandemic.

Hypothesis Six: Young people employees are less concerned that their workplace will be affected by the SARS CoV-2 pandemic.

The questionnaire used in this paper is structured in two parts: the first part about the impact of SARS-COV-2 on Romanian employees and the second part about demographical elements. We distributed the questionnaire on social media networks (Facebook and LinkedIn).

The sample consists of 251 respondents, out of which $80.4 \%$ female and $19.6 \%$ male. Out of all respondents, $0.7 \%$ were part of the Silent Generation (1928-1945), 2\% were part of the Baby Boomer Generation (1946-1964), 23\% were part of X Generation (1965 - 1980), 60.1\% were part of Millennial Generation (1981 - 1996) and 14.2\% were part of Z Generation (1997 - 
2012). $73.13 \%$ of respondents work in Bucharest and the rest of $26.87 \%$ work in the rest of the country.

The majority of $43.1 \%$ respondents said they work in a multinational company, $21.9 \%$ work in a public institution in the area like education, culture and health, 13.1\% work in an SME and $10.9 \%$ work in a microenterprise. Of all respondents $45.3 \%$ work for an employer with more than 249 employees, $21.6 \%$ of them work for an employer with 50-249 employees, $20.9 \%$ work for an employer with 10-49 employees and 10.1\% work for an employer with less than 10 employees.

Data that we collected based on this questionnaire were entered into R Studio and Excel. We developed a descriptive statistic for the questions of the questionnaire and then, we tested the hypothesis above.

Asking the question about how their workplace was affected by the crisis, the majority of the respondents, $41.2 \%$ of them said they will continue to work from home, then $18.9 \%$ of the total said they were not affected up to this moment, $17.6 \%$ of the total said the employer asked them to stop the activity for a period, $12.8 \%$ of them said they work from home and sometimes have to go to the workplace and the rest said they stop the activity with the agreement of employer or their workplace was suspended.

We were interested to find out how concerned people are because SARS-CoV-2 will affect their workplace. $35.8 \%$ of respondents are very concerned, $33.8 \%$ are quite concerned, $21.6 \%$ are less concerned and $8.8 \%$ are not concerned.

Only $23.6 \%$ of respondents said they already lost a part of their income as a result of SARS-CoV-2, 20.3\% said they do not know anything about losing income up to this moment and $56.1 \%$ said they didn't lose anything.

The majority of $63.5 \%$ respondents find out news about SARS-COV-2 from TV, $47.4 \%$ from social media, $35.8 \%$ from company manager, $32.8 \%$ from the internet, $24.8 \%$ from online media; only $10.2 \%$ of respondents find out news about SARS-COV-2 from the family doctor, $0.7 \%$ from WHO, $0.7 \%$ from Ministry of Internal Affairs and $0.7 \%$ from medical articles.

It seems that the majority consider the Government responds good enough at people concern, $42.3 \%$; the rest of $40.1 \%$ said not so good, $4.4 \%$ said very good and $13.1 \%$ said very bad.

Apart from work, in percent of $81 \%$ of the total, people are also concerned about them and family health, $18.2 \%$ are worried they will not be able to pay the loan rates, $28.5 \%$ are worried they will not be able to pay the bill if the employer reduces their income, $0.7 \%$ are worried they will not be able to conduct their activities, $0.7 \%$ are worried they will lose the payment for wedding and $0.7 \%$ are not worried.

The employer has established a specific communication strategy with the employees in 55.5\% of cases. In $68.6 \%$ of cases the employer provided hand and workplace hygiene products.

The employer sanitizes the workplace every time is necessary in $35.8 \%$ of cases, several times a day in $24.8 \%$ of cases, once a day in $18.2 \%$ cases, never in $15.3 \%$ of cases and whenever employees change their job duties in $5.8 \%$ cases. In $64.2 \%$ of cases the employer ensures flexibility of the work schedule. 
In $62 \%$ of cases, employees can work remotely. Regarding SARS-COV-2 impact, the employer has a well-established plan in $38 \%$ of cases, took minimal protection measures in $35.8 \%$ of cases and has activated or developed a crisis team in $15.3 \%$ of cases.

In $35 \%$ of cases, the business travel was affected very much and in $20.4 \%$ was significantly affected; only in $14.6 \%$ cases, the business travel was not affected by the virus. The epidemic affected very much the transport to work place in $19 \%$ cases and significantly in $35.8 \%$ cases.

\section{RESULTS AND DISCUSSION}

The testing hypothesis has as results the followings:

Hypothesis One: There is a direct relation between people concern their workplace will be affected by SARS-COV-2 and how well government respond to their concern. From those who declared they are very concerned their workplace will be affected by the virus, $15.8 \%$ declared the government respond well to them concern and $20.3 \%$ declared the government doesn't respond well. From those who declared they are not concerned at all their workplace will be affected by the virus, $7.5 \%$ declared the government respond well to their concern and $2.3 \%$ declared the government doesn't respond well. We can conclude that the hypothesis is partially true.

Hypothesis Two: People are less concerned their workplace will be affected by SARS-COV2 if the employer established a specific communication strategy regarding this medical crisis than the case if the employer doesn't establish a specific communication strategy regarding this medical crisis. From the data sample we can observe that when the company established a specific communication strategy regarding this medical crisis, $40 \%$ are not so concerned their workplace will be affected by SARS-COV-2. If the company doesn't establish a specific communication strategy regarding this medical crisis, $16.7 \%$ of the total are not so concerned their workplace will be affected by SARS-COV-2. From the results above we can say that hypothesis 2 is rejected.

Hypothesis Three: People are less concerned their workplace is affected by SARS-COV-2 if employer provides employees the opportunity to work remotely. It seems that $39.5 \%$ are not concerned their workplace will be affected by SARS-COV-2 if the employer provides the opportunity to work remotely and $13.3 \%$ are not concerned their workplace will be affected by SARS-COV-2 if the employer doesn't provide the opportunity to work remotely. We can observe a bigger value for concern than lack of concern in both situations, so the hypothesis is rejected.

Hypothesis Four: People from Bucharest are more concerned than the rest of the country regarding the workplace will be affected by the virus. In this case, we can see that $33.7 \%$ of people from Bucharest and 20\% of people from the rest of the country are not concerned regarding the workplace will be affected by the virus. In this case, we can say that we will accept the hypothesis.

Hypothesis Five: Women are more concerned than men regarding the workplace will be affected by the virus. In the sample we have more women than men. We observe that $30.3 \%$ of the total of women and $29.2 \%$ of the total of men are not concerned their workplace will be affected by the virus. People know this virus can affect their health so we can say this hypothesis is rejected. 
Hypothesis Six: Young people are less concerned their workplace will be affected by the virus. People born after 1981 are not concerned their workplace will be affected by the virus in percent of $32.3 \%$ and people born until 1980 are not concerned their workplace will be affected by the virus in percent of $23.5 \%$. We can say in this case that the hypothesis is rejected.

\section{FUTURE RESEARCH DIRECTIONS}

In conducting future research, the authors will consider aspects less or not highlighted in the current study such as communication between employee and employer, measures taken by the employer to reduce or eliminate risks to occupational health and safety, and overcoming the limitations the choice and sizing of the research sample.

\section{CONCLUSION}

The results of this research reveal how the working hypotheses in the second level of the analysis were confirmed or not regarding the impact of occupational and healthy risks on the sustainability of Romanian organizations under the SARS-COV-2 pandemic. In this regard, hypothesis $\mathrm{H} 1$ is partially true, the hypotheses $\mathrm{H} 2, \mathrm{H} 3, \mathrm{H} 5, \mathrm{H} 6$ are rejected, and the hypothesis $\mathrm{H} 4$ is accepted. In conclusion, there is a direct relationship between employees' concern that their workplace will be affected by the SARS CoV-2 pandemic and how well government responds to their concern, and employees from Bucharest are more concerned than those from the rest of the country that their workplace will be affected by the SARS CoV-2 pandemic.

\section{REFERENCES}

Ahmed, F., Kim, S., Nowalk, M.P., King, J.P., VanWormer, J.J., Gaglani, M., Zimmerman, R.K., Bear, T., Jackson, M.L., Jackson, L.A., Martin, E., Cheng, C., Flannery, B., Chung, J.R., and Uzicanin, A. (2020). Paid Leave and Access to Telework as Work Attendance Determinants during Acute Respiratory Illness, United States, 2017-2018. Emerging Infectious Diseases, [e-journal] 26(1). pp.26-33. https://doi.org/10.3201/eid2601.190743 [Accessed 1 March 2020].

Beaton, R., Stergachis, A., Thompson, J., Osaki, C., Johnson, C., Charvat, S.J., Marsden-Haug, N. (2007). Pandemic Policy and Planning Considerations for Universities: Findings from a Tabletop Exercise. Biosecurity and Bioterrorism: Biodefense Strategy, Practice, and Science, [e-journal] 5(4). https://doi.org/10.1089/bsp.2007.0029 [Accessed 1 March 2020].

Blake, K.D., Blendon, R.J., Viswanath, K. (2010). Employment and Compliance with Pandemic Influenza Mitigation Recommendations. Emerging Infectious Diseases, [ejournal] 16(2). pp.212-218. https://doi.org/10.3201/eid1602.090638 [Accessed 1 March 2020].

Council of the European Union. (1989). Council Directive 89/391/EEC of 12 June 1989 on the introduction of measures to encourage improvements in the safety and health of workers at work. ELI: http://data.europa.eu/eli/dir/1989/391/oj

Duncan, K. (2007). Pandemic flu: current threat and development of a preparedness framework. WIT Transactions on the Built Environment, 94. pp.473-485 DOI: 10.2495/SAFE070471 [Accessed 3 March 2020].

Harvard Global Health Institute. (2018). Global Monitoring of Disease Outbreak Preparedness: Preventing the Next Pandemic. [pdf] Harvard University, Cambridge, MA. Available at: < https://globalhealth.harvard.edu/ > [Accessed 2 March 2020]. 
Itzwerth, R., Moa, A. \& MacIntyre, C.R. (2018). Australia’s influenza pandemic preparedness plans: an analysis. $J$ Public Health Pol. [e-journal] 39. pp.111-124. https://doi.org/10.1057/s41271-017-0109-5 [Accessed 29 February 2020].

Jiang, X. (2009). The virtual SARS epidemic in Europe 2002-2003 and its effects on European Chinese. Health, Risk \& Society. [e-journal] 11(3). pp.241-256. https://doi.org/10.1080/13698570902887498 [Accessed 28 February 2020].

Lam, W.K., Zhong, N.S., Tan, W.C. (2003). Overview on SARS in Asia and the World. Respirology, [e-journal] 8. S2-S5. DOI: 10.1046/j.1440-1843.2003.00516.x [Accessed 27 February 2020].

Lee, B.Y., Brown, S.T., Cooley, P.C., Zimmerman, R.K., Wheaton, W.D., Zimmer, S.M., Grefenstette, J.J., Assi, T.M., Furphy, T.J., Wagener, D.K., \& Burke, D.S. (2010). A computer simulation of employee vaccination to mitigate an influenza epidemic. American journal of preventive medicine, [e-journal] 38(3). pp.247-257. https://doi.org/10.1016/j.amepre.2009.11.009 [Accessed 1 March 2020].

Murphy, S., Friesner, D., Rosenman, R. (2014). Firm Responses to the Crises of 2009. International Journal of Social Ecology and Sustainable Development. 5. pp.90-108. DOI: 10.4018/ijsesd.2014010107 [Accessed 27 February 2020].

Rebman, T., Wang, J., Swick, Z., Reddic, D., delRosario Jr., J.L. (2013). Business continuity and pandemic preparedness: US health care versus non-health care agencies. American Journal of Infection Control, [e-journal] 41(4). pp. e27-e33. https://doi.org/10.1016/j.ajic.2012.09.010 [Accessed 28 February 2020].

Rebman, T., Wang, J., Swick, Z., Reddic, D., Minden-Birkenmaier, C. (2013). Health care versus non-health care businesses' experiences during the 2009 H1N1 pandemic: Financial impact, vaccination policies, and control measures implemented. American Journal of Infection Control, [e-journal] 41(6). pp. e49-e54. https://doi.org/10.1016/j.ajic.2012.09.012) [Accessed 1 March 2020].

Smith, P.W., Hansen, K., Spanbauer, L., Duane, F.S. (2007). Pandemic influenza preparedness: A survey of businesses. American Journal of Infection Control, [e-journal] 35: 7. pp.484485 https://doi.org/10.1016/j.ajic.2006.11.008 [Accessed 28 February 2020].

Smith, R.D., Keogh-Brown, M.R., Barnett, T., Tait, J. (2009). The economy-wide impact of pandemic influenza on the UK: a computable general equilibrium modelling experiment. BMJ-British Medical Journal, [e-journal] 339. b4571 DOI: 10.1136/bmj.b4571 [Accessed 3 March 2020].

Torá-Rocamora, I., Delclos, G.L., Martínez, J.M., Jardí, J., Alberti, C., Manzanera, R., Yasui, Y., Clèries, R., Tobías, A., Benavides, F.G. (2012). Occupational health impact of the 2009 H1N1 flu pandemic: surveillance of sickness absence. Occupational and Environmental Medicine, [e-journal] $69 . \quad$ pp.205-210. http://dx.doi.org/10.1136/oem.2011.065003 [Accessed 28 February 2020].

Watkins, R.E., Cooke, F.C., Donovan, R.J., MacIntyre, C.R., Itzwerth, R., Plant, A.J. (2007). Influenza pandemic preparedness: motivation for protection among small and medium $\begin{array}{lllll}\text { businesses in Australia. BMC Public Health, [e-journal] 7. } 157 & \end{array}$ https://doi.org/10.1186/1471-2458-7-157 [Accessed 29 February 2020].

Watkins, R.E., Cooke, F.C., Donovan, R.J., Macintyre, C.R., Itzwerth, R., Plant, A.J. (2008). Tackle the problem when it gets here: Pandemic preparedness among small and medium businesses. Qualitative Health Research, [e-journal] 18(7). pp.902-912. doi: 10.1177/1049732308318032 [Accessed 3 March 2020]. 